\title{
DISTANCIAMENTO SOCIAL NA PERSPECTIVA DO SAGRADO: CORONAVÍRUS E AS NOVAS PRÁTICAS ESPACIAIS
}

\author{
Christovam Reis dos SANTOS FILHOS ${ }^{1}$ \\ Otávio José Lemos COSTA²
}

\begin{abstract}
Resumo
O presente texto mostra uma perspectiva de análise acerca do sagrado em sua dimensão espacial em um período de distanciamento social proveniente de uma pandemia que avança em escala planetária, afetando também templos religiosos e outros lugares sagrados. Assim, esse texto objetiva analisar o distanciamento social numa perspectiva do sagrado. Para isso, tomamos por base os noticiários jornalísticos referentes ao tema e associamos a um esteio teórico que valorize os significados espaciais das medidas acatadas pelas instituições religiosas e seus fiéis sobre no que concerne ao entendimento do sagrado. Considerando o medo que a doença propaga e as relações sociais cada vez mais frágeis, avançamos em um entendimento que as pessoas estão sendo direcionadas a olharem o sagrado por uma perspectiva mais líquida, moldada ao contexto pandêmico causado pelo COVID-19. Portanto, nossa análise indica uma valorização do indivíduo perante o sagrado, no qual assume uma postura fluida quanto à sacralização de espaços privados, ressignificando o lar como enquanto um lugar seguro perante uma doença e ponto de encontro com o transcendente.
\end{abstract}

Palavras-chave: Espaço sagrado; Distanciamento social; Coronavírus; significados; Fluidez.

\section{SOCIAL DISTANCING FROM THE PERSPECTIVE OF THE SACRED: CORONAVIRUS AND THE NEW SOCIAL PRACTICES}

\begin{abstract}
The present text shows an analysis perspective with regard to the sacred in its spatial dimension at a time of social detachment due to a pandemic that is advancing on a planetary scale, affecting religious temples and other sacred places, including fostering distinct and even conflicting ideological positions among religious leaders. Thus, this text aims to analyze social distance in a perspective of the sacred. For this, we search the news from the journals related to the theme and to link it to a theoretical support that values the spatial meanings of the measures taken by religious institutions and their faithful regarding the understanding of the sacred. Considering the fear that the disease spreads and social relations increasingly fragile, we proceed in an comprehension that people are being directed to look at the sacred from a more liquid perspective, molded to the pandemic context caused by COVID-19.

\footnotetext{
${ }^{1}$ Doutorando pela Universidade Estadual do Ceará - UECE. E-mail: santosfilho20@gmail.com

${ }^{2}$ Professor Doutor pela Universidade Estadual do Ceará - UECE. E-mail: otavio.costa@uece.br
} 
Therefore, our analysis suggests an appreciation of the individual towards the sacred, in which he assumes a fluid attitude regarding the sacredness of private spaces, showing other meaning for the home while a safe place against the illness and a meeting place with the transcendente.

Keywords: Sacred space, Social distance, Coronavirus; Meanings; Fluidity.

\title{
DISTANCIATION SOCIALE DANS LA PERSPECTIVE DU SACRÉ: CORONAVIRUS ET LES NOUVELLES PRATIQUES SPATIALES
}

\begin{abstract}
Résumé
Le présent texte montre une perspective d'analyse sur le sacré dans sa dimension spatiale dans une période de détachement social provenant d'une pandémie évoluant à l'échelle planétaire, affectant également des temples religieux et d'autres lieux saints. Ce texte vise à analyser la distance sociale dans une perspective sacrée. Pour cela, nous prenons pour base les informations journalistiques sur le sujet et nous associons à un support théorique qui valorise les significations spatiales des mesures suivies par les institutions religieuses et leurs fidèles en ce qui concerne la compréhension du sacré. En considérant la peur que la maladie propage et les relations sociales de plus en plus fragiles, nous avançons dans une compréhension que les gens sont dirigés vers le sacré par une perspective plus liquide, façonnée par le contexte pandémique causé par le COVID-19. Notre analyse indique donc une mise en valeur de l'individu face au sacré, dans lequel il assume une posture fluide quant à la sacralisation d'espaces privés, en rendant le foyer reséquent comme lieu sûr face à une maladie et point de rencontre avec le transcendant.
\end{abstract}

Mots-clés: Espace sacré, Éloignement social, Coronavirus; Significations; Fluidité.

\section{INTRODUÇÃ̃}

Esse texto é escrito perante o aumento exponencial do Sars-Cov-2, popularmente conhecido por coronavírus, responsável pela pandemia iniciada na China ainda em 2019, mas que no Brasil acentuou sua contaminação, sobretudo no mês de março de 2020 e onde até o momento da redação do texto já eram mais de sessenta e um mil casos $(\mathrm{G} 1,2020)$. Lembrando a célebre frase de Cosgrove (1998, p. 92) “a geografia está em toda parte”, questionamos: que consequências esta pandemia traz para pensarmos uma espacialidade associada ao sagrado?

Essa reflexão decorre das repercussões políticas sobre as instituições religiosas decorrentes da disseminação do coronavírus em nosso país, sobretudo com a determinação de fechamentos de templos religiosos. Algumas manchetes 
chamaram a atenção, pela repercussão e atitudes incertas e preocupantes por parte de alguns líderes religiosos que motivados por razões contrárias, se mostravam refratários às determinações estabelecidas por decisões dos poderes locais, ora estaduais ou municipais com relação ao isolamento social.

Chamamos atenção, de modo resumido, para alguns destaques noticiados nos dias em que propomos a redação deste texto. Um deles diz que: "Evento fechado em igreja evangélica espalha coronavírus por toda a França" (ÉPOCA, 2020), mostrando além da alta taxa de contaminação, houve negligência sanitária por parte dos dirigentes do templo, não considerando os riscos de uma aglomeração desse porte.

Aliada a negligência vemos também a oposição entre dirigentes de templos. Observamos na reportagem intitulada "De cultos online a 'não leia notícias sobre pandemia': como as religiões estão lidando com o coronavírus no Brasil" (MACHADO, 2020), ideias opostas, pois enquanto alguns pastores recomendaram desprezarem os noticiários e não faltarem os cultos, outros recorreram ao distanciamento fraterno e aos cultos online.

E essa divergência doutrinária se acirrou de tal intensidade que pastores foram denunciados por charlatanismo (SERNA, 2020), outros denunciados pelo Ministério Público (CHAGAS, 2020) e outros foram infectados e transmissores do COVID-19 (GREGÓRIO, 2020). O conteúdo jornalístico mostra a incoerência entre a fé e a razão existente, sobretudo no meio evangélico, uma vez que, como mostra uma das reportagens citadas, as autoridades católicas aceitaram com maior serenidade as recomendações decretadas pelas autoridades governamentais.

Por outro lado, há posturas evangélicas opostas aos casos acima mencionados entre as novidades jornalísticas. $\mathrm{E}$ a grande ferramenta para isso foi à conexão virtual, como nas notícias anunciadas respectivamente sob os títulos: "Coronavírus: uma oportunidade para a missão digital" (MOTTA, 2020) e "Pastor decide batizar jovem em casa devido a restrições pelo coronavírus, na Itália" (GUIAME.COM.BR, 2020). Ambas defendem que os templos religiosos devem se adaptar as mudanças forçadas pela pandemia e enxergam na conectividade social como manobra para manter a fé e a fraternidade mesmo sem o contato físico coletivo. 


\section{METODOLOGIA}

Do que foi lido e aqui exposto, nos apoiando em Cosgrove (1998) e o entendimento que a geografia cultural tem sobre o espaço para tecer algumas considerações sobre a fluidez espacial demonstrada no campo da religião frente ao coronavírus. Dessa forma, percebendo a relação que a geografia tem com a vivência cultural das pessoas, seja em espaços aparentemente opulentes ou em locais que não são percebidos pelas elites culturais e ressaltando que "significados constitui a palavra-chave da geografia cultural renovada" (CORRÊA e ROSENDAHL, 2008, p. 75), por que não avançar na reflexão sobre o sagrado e esse presente distanciamento social existente nas instituições religiosas?

Desse modo, objetivamos no presente texto compreender o distanciamento social na perspectiva do sagrado. Buscamos a compreensão a partir de um "olhar geográfico" (HISSA, 2002) que nos conduza além das aparências formais e analisar os significados calcados numa atitude filosófica na qual tencionamos uma maior compreensão da realidade e assim, compreendermos novos significados a partir do fenômeno do distanciamento social traz para o entendimento de novas espacialidades.

Para isso, nosso esteio teórico-metodológico se apoia nas interpretações acerca da liquidez espacial vivenciada nos dias atuais. Entendemos que as relações sociais ocorrem de maneira fluida e a espacialidade envolvida nessas relações contribui para serem ressignificadas de modo a se conformarem simbolicamente, segundo a proposta de Cassirer (2004) que defende o homem como um animal simbólico e por isso permeados de símbolos que moldam sua realidade.

Em sua obra “Modernidade Líquida” (BAUMAN, 2001), este autor nos mostra que a modernidade sólida é transplantada para uma modernidade líquida, pois os fenômenos sociais transbordam e avançam em lugares antes imagináveis. Dessa forma, procuramos observar como a liquidez de determinados fenômenos influencia a religião, pois as relações entre as pessoas criam símbolos que se moldam por uma constante sensação de incerteza e de rompimento com as convicções perpassadas por metanarrativas. Assim, o 
sagrado em tempos líquidos se ressignifica em meio a um ambiente social de persistente medo e ávida por novidades que se refletem na prática religiosa.

Destaca-se ainda a intensificação do medo e a busca por segurança na modernidade líquida. Como consequência, um fenômeno como o coronavírus torna ainda mais alarmante o ambiente de temor, ou em outras palavras,

Afinal, viver num mundo líquido-moderno conhecido por admitir apenas uma certeza - a de que amanhã não pode ser, não deve ser, não será como hoje - significa um ensaio diário de desaparecimento, sumiço, extinção e morte. Permeadas de medo, a religião se torna uma fuga para tornar esse medo "administrável" (BAUMAN, 2008, p. 12)

Com as notícias publicadas pela imprensa, pretendemos analisar a postura líquida das instituições religiosas em usar o ambiente virtual como forma de administrar o medo da doença e obedecer às recomendações decretadas pelas autoridades governamentais. Ressaltando que o distanciamento social tem sido propagado de maneira emergencial para combate à pandemia no país.

\section{DISCUSSÃO}

Como desdobramento de ordenamentos governamentais no sentido de proteger a população da COVID-19, os templos religiosos foram recomendados a fecharem suas portas. A partir desse acontecimento se estabelece uma discussão a respeito das espacialidades do sagrado e consequentemente um movimento reativo que reconfigura essas aquelas espacialidades no que concerne ao exercício da fé.

O sagrado tem como premissa básica o seu aspecto numinoso, isto é, algo descrito por alguém que passou por uma experiência com o transcendente. Ao explanar sobre o sagrado, Otto (2007, p. 44) diz que "ele é irracional, ou seja, não pode ser explicitado em conceitos, somente poderá ser indicado pela reação especial de sentimento desencadeado na psique”. Assim, o sagrado só pode ser descrito e expresso por símbolos, uma vez que nele contém elementos racionais e irracionais. Em virtude dessas manifestações simbólicas que podemos dizer que o sagrado também se espacializa. Rosendahl (2012, p. 73) inicia uma 
discussão sobre a dimensão espacial do sagrado asseverando que este "irrompe em determinados lugares, qualificando-os em uma dimensão religiosa”. Essa qualificação é simbólica, pois há uma relação entre quem sente a irrupção e o objeto ou local em que o sagrado aparece.

O esteio teórico proposto por Mircea Eliade nos remete à manifestação do sagrado que pode estar presente no real, assim expresso através de objetos, ritos ou lugares em que o homem religioso significa ser diferentes dos outros que o circundam. Ou seja, "não interessa a Eliade a subjetividade do crente, mas o modo como estas hierofanias se estruturam, ou seja, a descrição das estruturas do próprio sagrado" (GROSS, 2017, p. 48), Assim, as circunstâncias em que algo foi sacralizado refletem ao contexto histórico vivido naquele momento. O próprio Eliade (2008) apresenta o seu principal conceito, a hierofania, indicando que ela ocorre em objetos físicos, mas também em rituais ou locais específicos, independentes de sua fixação no território. Além disso, ele remete a hierofania a uma seleção simbólica. Ele diz que "uma hierofania pressupõe uma escolha, uma nítida separação do objeto hierofânico relativamente ao mundo restante que o rodeia" (ELIADE, 2008, p. 19). Assim, temos uma variabilidade de possibilidades para delimitar simbolicamente um espaço sagrado.

Os templos religiosos são considerados espaços sagrados por aqueles que o frequentam. Assim a assiduidade e participação dos eventos congregacionais fazem parte da confirmação de fé e moldam a realidade dos fiéis, pois participar das reuniões litúrgicas promove o reavivamento do sagrado, ou conforme Eliade (1985), o eterno retorno, pois a sacralidade se espacializa pela sua repetição temporal.

Contudo, em período de isolamento social, os fiéis são orientados a permanecerem em casa, essa rotina espiritual anterior passa por mudanças. Agora o "mandamento do Senhor" é buscar a internet e de sua casa participar das atividades litúrgicas através dos meios de comunicação ou via "online”. É semelhante ao proposto pelos pastores da TV décadas atrás. A diferença é que na época em que o culto televisivo ganhou força, não havia como o fiel interagir simultaneamente. 
Todavia, a conexão pelas redes sociais permite um novo tipo de interação simbólica com o sagrado. Mas até que ponto isso é eficiente? Qual o interesse de somente agora com a restrição de ir ao templo os fiéis poderem participar de atividades do sagrado em suas residências? Como o sagrado se manifesta no âmbito do lar sem o encontro congregacional?

Observamos inicialmente o discurso daqueles que acolheram as restrições governamentais, pois eles apostam na internet para manter os cultos. O pastor Marcos Botelho, de uma igreja evangélica de São Paulo explicou da seguinte forma: "Não queremos criar pânico. Acreditamos que Deus está no controle de todas as coisas, mas queremos ajudar o Brasil a não espalhar o vírus de maneira rápida e não ocupar nossos leitos de hospitais. Nos vemos [sic.] online” (MACHADO, 2020). A preocupação sanitária é a prioridade e o apelo da conexão online foi enfatizado. Neste mesmo direcionamento, o pastor Levi Araújo, afirma "é importante que, nesse momento, denominações religiosas se posicionem com o objetivo de proteger seus fiéis e o restante da população" (Op. Cit., 2020). A proteção dos fiéis nesse momento é física, e não espiritual. Logo, ir aos templos põe em risco a saúde dos fiéis, mesmo que estejam se alimentando espiritualmente. Assim o templo permite uma mudança de significado, pois é passível do vírus como qualquer outro local profano, amorfo, igual aos demais. Os locais amorfos fazem parte do cotidiano do homem religioso (ELIADE, 1979).

Paradoxalmente, o fiel ao assistir cultos e outros programas religiosos através de emissoras de TV ou da internet, acompanha o culto de casa e o que ele vê é o mesmo templo em que frequenta o mesmo dirigente, o mesmo altar e músicos, contudo da tela de seu computador, televisor ou aparelho celular. O que seria o sagrado então? O local que ele visualiza pela conexão virtual ou a própria conexão que o faz visualizar o espaço sagrado?

O que ocorre em tempos líquidos é uma exacerbação das práticas individuais. Com o incentivo tecnológico isso pode ser reforçado e com as restrições do poder público, isso passa a ser exaltado. O entendimento passa por uma ressignificação, pois o sagrado está "no próprio sujeito humano, considerado enquanto indivíduo, na sua relação direta com Deus, através da 
leitura individual e silenciosa dos textos bíblicos e de outras práticas de devoção pessoal” (DUQUE, 2012, p. 77), inclusive os cultos online.

Podemos então afirmar que mesmo sem a atual doença, a religião na modernidade líquida já sinalizava um individualismo diferente do que ocorria a tempos anteriores. Como já afirmava Oliveira (2017, p. 72) "As redes sociais como Facebook, Twitter, Instagram, YouTube; aplicativos como Whatsapp, Telegram possibilitaram ao fiel diferentes experiências e vivências com o sagrado". Contudo, mesmo com práticas individuais, os encontros congregacionais eram estimulados e até mesmo cobrados pelos dirigentes religiosos, ao ponto de alguns templos acomodarem milhares de pessoas e formarem grandes aglomerações. A novidade é a exortação para um distanciamento físico como medida de obediência e demonstração de fé.

Para a geografia, o distanciamento é algo que altera as relações socioespaciais. Distância, separação entre dois corpos por meio de uma área geométrica, remete ao espaço uma adaptação relacional entre as pessoas distanciadas. Fisicamente realoca as pessoas a vivenciarem de maneira mais individual como modo de proteção de algo que se propaga por contato.

Destaca-se que um dos desdobramentos da modernidade líquida é a compressão espaço-tempo que aproxima as distâncias, pois os deslocamentos são mais velozes, mediante a tecnologia nos transportes de mercadorias, pessoas e informações. A distância deixou de ser uma barreira, para interação interpessoal, pois

Quem enfatizava a unidade entre os povos também aceitava a "irrealidade do lugar" num espaço fragmentado. Celebrando a aniquilação do espaço por meio do tempo, a tarefa era relançar o projeto iluminista de emancipação humana universal num espaço global tornado coeso mediante mecanismos de comunicação e de intervenção social. Esse projeto implicava, porém, a fragmentação espacial por intermédio da coordenação planejada, por meio de um ritmo mais acelerado (HARVEY, 2017, p. 245).

Ou seja, a distância deixou de ser um problema, mas continuou moldando as afinidades sociais, pois sem a aproximação espacial física, as relações se tornaram acessíveis, porém fragilizadas. A comunicação sobrepujou a vivência e a ordenação espacial se tornou majoritária sobre as experiências 
interpessoais, mudando e influenciando o entendimento sobre o que é ser próximo do ponto de vista social.

Contudo, esse distanciamento social imposto não se atém aos valores culturais e nem à ótica das religiões nas aglomerações, pois nas igrejas é comum as pessoas estarem aglomeradas em proximidade com o altar do templo e também pela confraternização entre os irmãos uma vez que abraçar cantar e falar juntos são considerados como gestos de irmandade dentro das liturgias religiosas, sobretudo evangélicas.

Aqui podemos inserir o entendimento humanista de Tuan (2013), ao se reportar sobre os espaços dotados de afetividade, dos quais o corpo é um deles. Assim, em tempos de quarentena, passam por um aprofundamento do olhar pessoal sobre o mundo que os circundam. A princípio o corpo é a primeira escala interpretativa que o indivíduo tem sobre o espaço. "Em outras palavras, os princípios fundamentais da organização espacial encontram-se em dois tipos de fato: a postura e estrutura do corpo e as relações entre as pessoas" (TUAN, 2013, p. 49), o que mostra que o contato com o sagrado passa inicialmente pelos sentidos e percepções pessoais.

Por isso, a confraternização entre membros de uma mesma igreja é louvável para os membros, pois é a relação entre eles que irrompe o sagrado. "Distância tem conotação de graus de acessibilidade e também de preocupação" (TUAN, 2013, p. 63). Assim, os espaços sagrados são locais onde essas interações entre corpos vivos se acontecem, onde também aprofundam o acesso e eliminam as preocupações. E dessa junção há o contato entre eles e o transcendente.

Por essa razão, alguns líderes religiosos, sobretudo pastores evangélicos contrapõem o fechamento dos templos. Um exemplo disso é o Pastor Silas Malafaia, da Igreja Assembleia de Deus Vitória em Cristo, quando afirma: "Como pastor, acredito que a igreja tem que ser o último reduto de esperança para o povo. [...] a igreja precisa estar de porta aberta" (MACHADO, 2020). Acredita-se que isso é algo limitante do que seja a vivência comunitária, enfatizando o espaço sagrado materializado pelo templo como essencial à fé das pessoas. 
Porém, a internet tem trazido uma possibilidade de pensar esse distanciamento social no âmbito do sagrado por meio da visualização do espaço sagrado por meio de transmissões ao vivo dos cultos. A ideia é que a conexão traz a afluência virtual como possibilidade de fraternidade, pois percebe o espaço sagrado pela vinculação presente na rede. Neste sentido somos consoantes à afirmação de Pereira (2014) que entende o espaço sagrado como encontro, nesse caso virtual.

Com as recomendações do governo sobre o isolamento social, os cultos são transmitidos online, porém como fiel entende o sagrado nessa perspectiva, visto que ele foi obrigado a se afastar do da "casa de Deus"? Lembrando que o templo é visto como o centro do mundo (ELIADE, 1979) e um espaço de afetividade (TUAN, 2013). Nesse caso o corpo passa a ser escala de acesso às dimensões do mundo vivido em um ambiente (casa) escolhido por ele. Mesmo que a relação via internet seja uma relação líquida, na qual, segundo Bauman (2011) as pessoas têm relações frágeis, no âmbito religioso o fiel se distancia fisicamente de outros fiéis, enquanto ele mesmo, pela escala corporal sagrado, passa a ser o centro do mundo no local em que está.

A transmissão dos cultos online é diferente do que se entende por exercício da sacralidade cristã mais tradicional, pois os membros ficam sozinhos diante de um computador ou celular e o contato com sagrado se torna individual, e não coletivo. Essa situação é semelhante ao comportamento social em redes sociais, no qual a qualidade da conexão passa a ser menos importante que a quantidade de conectados (BAUMAN, 2011). No campo religioso, faz dessa relação entre fiel e templo algo frágil. Então o espaço sagrado é entendido por uma visão pessoal, no qual o indivíduo passa a abrigar interiormente aquilo que deveria ser coletivo, sacralizando coisas que até então eram perceptivamente profanas.

Sobre a alternativa de cultos em casa de maneira individualizada pela transmissão online dos cultos, a religiosidade interna da pessoa frente ao que ela entende como contato com a divindade do templo torna este uma figura contemplativa. Ou seja, a casa onde se encontra se torna centro do mundo, mas também escala de mediação entre o sagrado e homem e vivenciada individualmente pela relação particularizada pela internet. $\mathrm{O}$ templo passa a ser 
um espaço de representação (GIL FILHO, 2008), pois o fiel vê o local de prática religiosa na transmissão, aproximando-se do sagrado mediado pela sua residência.

Com essa prática a fragilidade das relações coletivas tende a se atenuar, pois não há convívio religioso e o fiel assume exclusivamente uma postura individual, pela ausência dos encontros. A fragilidade acontece porque o fiel na internet

faz isso reduzindo a duração desses contatos e, por conseguinte, enfraquecendo os laços, muitas vezes impondo o tempo - em flagrante oposição à sua contrapartida off-line, que, como é sabido, se apoia no esforço continuado de fortalecer os vínculos, limitando severamente o número de contatos à medida que eles se ampliam e se aprofundam (BAUMAN, 2011, p. 19).

Assim, as relações sociais religiosas tendem a se fragmentarem de modo mais intenso. Por conseguinte, há um deslocamento do sagrado saindo do local físico para um ciberespaço religioso, definido como algo que conecta o fiel ao que ele entende ser a local de adoração e prática religiosa.

Podemos afirmar que o distanciamento social na perspectiva do sagrado é a transformação do espaço sagrado físico do templo para o individualismo do fiel. Espacialmente, isso ocorre pela relação daquilo que Haesbaert (2014) chama de território-rede, que compreende aos espaços reticulares, cujas zonas são interrompidas. As transmissões de cultos online remetem a este tipo de território, uma vez que há a interrupção física do fiel com o templo, mas há conexão entre eles pela rede.

Não desprezando a situação que a pandemia gera nas coletividades, a alternativa de uso dos territórios-rede se faz importante para manter o contato religioso e diminuir o medo de propagação do vírus. Até porque "no que se refere ao pânico, quanto mais intensos e terríveis forem, mais depressa exaurem nossas reservas emocionais e sua própria capacidade de nos aterrorizar e enervar" (BAUMAN, 2011, p. 67). Por isso há uma demanda religiosa de ressignificar o espaço sagrado para suprir o desânimo apresentados pelas notícias acerca da doença. 
Portanto, a religiosidade em tempos de coronavírus é a passagem de um entendimento do sagrado da coletividade para o individual, no qual cada um se torna mediador ao divino. Então o fiel assiste a transmissão pela internet porque associa a sacralidade à conectividade com o templo e ao sacerdote que administra a reunião. É uma demonstração de fluidez na relação religiosa, todavia o sagrado é fragilizado pela transmissão, pois perdida ou impossibilitada a conexão da internet o sagrado não ocorre e instantaneamente ele se sente no espaço profano, no cotidiano, amorfo, sem forma (ELIADE, 1979) e sem a ordem do transcendente. É o resultado de uma relação líquida, frágil e efêmera.

Por outro lado, a mesma conexão, quando possível, torna o fiel reticularmente mais próximo do sagrado, uma vez que a transmissão que está sendo feito e sua casa e seu computador passa a serem objetos dotados de sacralidade. É um meio no qual ele tem acesso com a divindade e mesmo com o medo da doença, isolado, líquido e fragilizado, ele vê possibilidade de interação transcendental por meio da transmissão litúrgica que o ocorre pela internet.

Contudo, há ainda outras possibilidades noticiadas por conta da quarentena causada pelo coronavírus. Uma delas é uma forma inusitada de manter a congregação nos templos, porém sem promover a aglomeração de fiéis. Foi intitulada de "Drive In Church" (GRYBOSK, 2010), movimento no qual os fiéis foram de carro, no dia 22/03/2020, para o estacionamento do templo e no interior de seus veículos, participaram das atividades rituais que ocorriam no templo.

O contexto geográfico para o exercício do sagrado nesse caso é uma adaptação do espaço sagrado do templo. O estacionamento que em períodos sem quarentena é um espaço profano indiretamente vinculado ao sagrado, Rosendahl (2006). Por sua vez, em período de distanciamento social a aglomeração de pessoas dentro de seus carros apresentou uma sacralidade manifestada por estar próximo do templo e dali ser possível o desenvolvimento das práticas litúrgicas daquela congregação. A carga simbólica continua emanando do templo, porém os seus arredores são sacralizados mediante a interrupção causada pelo distanciamento social. 
Outra perspectiva é assumir o lar como espaço sagrado. Esta se assemelha a assertiva anterior, só que por pontos originais distintos. Enquanto naquela o sagrado ocorre no templo e o estacionamento está vinculado e ele, nessa o sagrado se manifesta no encontro e a casa está vinculada a ele. Para Coulanges (2006), algumas religiões antigas eram domésticas, de caráter familiar, inclusive herdamos o termo "lar" de lareira, o fogo permanentemente aceso na casa e representava os antepassados sacralizados. Assim a família se reunia e por meios rituais em volta da lareira para manter o contato com os deuses ancestrais.

Existe uma percepção de um grupo quando se toma o encontro residencial como manifestação do sagrado. Isso significa que o sagrado significa para o fiel um sentimento de interação com o transcendente simbolizado pela união de pessoas que compartilham da mesma realidade. Isso só pode ser feito por experiências religiosas em conjunto, pelo encontro. Observamos em uma das reportagens a visão do cantor gospel Alessandro Villas Boas, que explanou em formato de vídeo no YouTube:

Irmãos que essa estação que a gente está passando no planeta terra nos leve a perceber que a gente precisa dar ênfase nas casas, dar ênfase nas pessoas, dar ênfase em discipulado, dar ênfase na igreja viva e eficaz, na igreja que construímos dentro das pessoas e não para as pessoas (BOAS, 2020).

Nesse sentido o templo se reveste de uma sacralidade na qual o fiel estabelece uma relação imediata. Ou seja, ele é sacralizado mediante os rituais do sagrado que ocorre no âmbito de suas dependências, porém essa mesma hierofania pode acontecer fora dele, retirando seu significado de recinto do sagrado. Interpretando a fala do cantor evangélico, as casas e as pessoas tem maior primazia para conexão com o transcendente. Isso gera duas acepções acerca da manifestação do sagrado. A primeira é que as casas podem ser um local de comunhão entre os fiéis, assim o sagrado irrompe pelo encontro familiar direcionado para o transcendente. A segunda transparece a igreja construída dentro das pessoas, ou seja, algo percebido e construído ontologicamente em cada um, tornando-se mais importante que um espaço 
físico. Em ambos, o discurso religioso substancia simbolicamente um elo entre o sagrado com a realidade social (GIL FILHO, 2008).

Em concordância com o cantor gospel, temos uma explanação também documentada em reportagem sobre a prática cristã residencial. A notícia titulada de: Home church: Quarantine can be a time to draw closer to God3 é uma maneira em que Timothy Head (2020) expôs a necessidade dos cristãos ocidentais assumirem uma perspectiva diferente de comunhão e contato com o sagrado, uma vez que as aglomerações estão interditadas pelas autoridades, sobretudo nos Estados Unidos, que até o momento era o novo epicentro da doença no mundo (R7.COM, 2020). Segundo o repórter do The Christian Post, os fiéis têm uma nova oportunidade de se aproximar de Deus. Ao dizer isso, ele confronta os métodos tradicionais de reunião, sobretudo nos locais de grandes aglomerações com as megachurches espalhadas não só entre os norteamericanos como também em solo brasileiro.

Ele expõe seu argumento usando o caso dos cristãos existentes em partes da Ásia, como na China, cujas reuniões são clandestinas e ocorrem nas casas dos fiéis. Ele aponta um número de trinta milhões de pessoas que usam os lares como espaço sagrado. No Brasil a procura por grupos menores também ocorre, conforme Martins (2012), ou seja, reuniões em casa, cujas famílias isoladas em sua casa podem experimentar da fé pela prática ritual entre os membros da casa. Ele cita a oração, conversas e ensinos que já fazem parte dos templos, porém agora praticados em casa.

De fato, na Ásia as igrejas domésticas não são novidade. Inclusive o coronavírus tem sido motivo para o Partido Comunista Chinês (PCC) intensificarem a perseguição contra cristãos (HAYWARD, 2020). A repressão do governo chinês faz com que as congregações cristãs assumam espacialidades diferentes das tradicionais que adotam templos para prática religiosa.

Há estudos geográficos sobre igrejas consideradas clandestinas no continente asiático, uma vez que elas se moldam peculiarmente em relação às pressões governamentais. Sobre as igrejas em lares de Singapura, Kong (2002) as classifica como algo não oficialmente sagrado e que nos remete a uma

\footnotetext{
${ }^{3}$ Igreja em casa: quarentena pode ser um momento para se aproximar de Deus (Tradução nossa).
} 
"conception and meaning of sacred place are malleable in a secular, multireligious context"4 (KONG, 2002, p. 1585), no qual existe uma adaptação fluida sobre os modos de experienciar o sagrado. O termo não sagrado se refere nesse caso específico ao não uso de templos ou ainda alguns casos em que os lares são modificados estruturalmente para o exercício da fé.

No caso brasileiro em que há liberdade de culto e de crença, conforme declara à Constituição, o impacto do distanciamento social traz a reflexão das reuniões domésticas como uma alternativa segura contra o vírus sem perder de vista a essência do encontro como algo sagrado. O espaço doméstico é ressignificado a partir do momento que as pessoas ali se reúnem configurando, portanto, uma sacralidade fluida que se desfaz no momento em que o propósito da assembleia deixa de ser o contato transcendental.

Nesse sentido a reunião doméstica segue uma alternativa na lógica da fluidez, contudo de maneira off-line, pois ela se faz e desfaz rapidamente, a partir do encontro e práticas rituais. Após o encontro ocorre uma dispersão das pessoas que pode ser até mesmo dentro de casa. Um exemplo disso seria uma família pai, mãe e dois filhos, que num domingo para os seus afazeres e se deslocam para uma parte de sua residência e ali praticam os rituais religiosos. Essa aproximação doméstica é evocada pelo sagrado e faz com que aquele momento seja diferente de outros. Nesse caso, o coronavírus estaria sendo um motivo de isolamento social, mas incapaz de conter o contato com o sagrado.

Essa alternativa consegue superar a ausência do ajuntamento pessoal que a virtualidade não permite. As reuniões virtuais extrapolam o princípio de congregação, ignorando a máxima da religião cristã em que o espaço sagrado é a assembleia, resultado do ensinamento de Jesus, isto é, onde houvesse dois ou três em seu nome ali estaria (BIBLIA SAGRADA, Mateus, 2002).

\section{RESULTADOS}

Diante da pandemia e por meio das reportagens publicadas, observamos a existência de uma discussão, muitas vezes aportada por um cunho ideológico no que concerne à permanência doe cultos religiosos em espaços sagrados.

\footnotetext{
4 “concepção e significado de lugar sagrado são maleáveis em um contexto secular e multirreligioso" (tradução nossa).
} 
Alguns líderes religiosos de algumas igrejas evangélicas insistem em manter seus templos abertos, seguindo a lógica do espaço sagrado materialmente visível na paisagem. Inclusive com apoio do presidente da República que "tem cedido ao lobby evangélico por meio de declarações e gestos efusivos e, mais recentemente, no dia 26 de março, do polêmico decreto que inclui as igrejas na lista de serviços essenciais" (DIP et al., 2020), mostrando que o espaço sagrado construído é simbolicamente forte no país.

A inovação nesse período de distanciamento social gerou alternativas que mantenham o espaço sagrado na percepção dos fiéis sem, contudo, se expor ao coronavírus. Portanto, o presente texto oferece algumas considerações no que diz respeito ao sagrado e como este pode se apresentar espacialmente de maneira fluida no atendimento à necessidade dos fiéis. Dentre as possibilidades ressaltamos as reuniões online e as reuniões em lares.

As duas possibilidades que apresentamos, reuniões online ou domésticas apresentam uma espacialidade particular de tempos líquidos. O sagrado se molda espacialmente conforme as necessidades individuais dos fiéis. As reuniões online podem ser uma exacerbação individualista e superficial trazida à tona pela modernidade líquida, mais particularmente acentuada pelo medo do coronavírus. Enquanto isso, as reuniões domésticas podem ocasionar uma postura religiosa tribal, isto é, em grupos sectários, com suas próprias preferências.

O medo de propagação do vírus foi um elemento desencadeador para mais uma desconfiança perante as metanarrativas religiosas. A incerteza de que o local sagrado resguarde a saúde do indivíduo faz com que ele se aprisione não somente por obediência às autoridades, mas por duvidar que a relação entre ele e o transcendente no templo seja eficaz para preservação do corpo. Simultaneamente, o fiel também apresenta uma nova concepção de adoração. Um pensamento que se articula na substituição do templo pela comodidade e segurança do lar. A busca por segurança, aliás, é uma das características pósmodernas que ajudam no processo de uma "sociedade líquida" no tange às relações humanas.

No contexto espacial, o distanciamento das pessoas na perspectiva do sagrado nos traz apontamentos que indicam para uma seletividade individual 
da hierofania. O espaço sagrado passa a ser reticular, e não mais expansivo. Organiza-se em redes que mesmo distantes geometricamente, seguem interligados virtual e perceptivamente. Assim como a disseminação da doença se propaga de modo hierárquico, seguindo os espaços luminosos, o sagrado é geograficamente distribuído pela hierarquia simbólica da internet, cujo self é a escala de apresentação do sagrado. Aos que possuem maior conectividade podem se interligar a mais grupos e modelos de religiosidade, por outro lado, quem possui dificuldades de interação virtual acabam se afastando ou se isolando das práticas religiosas.

\section{CONSIDERAÇÕES FINAIS}

Com o exposto acima, percebemos que a pandemia causada pelo SarsCov-2 em 2020 trouxe impactos não só na dimensão sanitária, política e econômica, mas também no campo religioso. Os cuidados contra o vírus trouxeram reflexões, posturas e atitudes referentes ao modo de olhar para o sagrado.

Entendemos que o distanciamento social sob a perspectiva do sagrado resulta numa nova maneira de comunicação espacial entre o homem e o transcendente. $O$ indivíduo passa a ser escala de referência e o lar é ressignificado como o lócus intermediador do fiel com o transcendente, seja por modo virtual, seja em pequenas nucleações familiares.

Certificamos que a liquidez da modernidade direciona para relações religiosas mais individualistas, porém frágeis. Com a repercussão em larga escala do medo da doença, as relações se confinam e se tornam fluidas e mais dependentes do vínculo virtual.

O medo da doença é acompanhado por uma carga de incerteza da proteção acerca da propagação do vírus dentro dos templos. Essa indefinição irrompe uma concepção do sagrado que valoriza os atos particulares e domésticos. Agora a segurança do fiel se estabelece pelo grau de distanciamento que ele tem dos demais fiéis que com ele não residem.

Portanto, durante essa quarentena, podemos observar a dimensão dos tempos líquidos. É evidenciado um meridiano na sociedade a partir de posições 
ideológicas e política. Entretanto, vislumbramos uma transformação no modo de sentir, pensar e vivenciar o sagrado. Entre os que aderem o lar como local de encontro para suas práticas religiosas, molda o sagrado para uma dimensão mais particular. Por outro lado, a interação virtual traz uma sensação de comunhão com o sagrado já estabelecido, agora em um contato simbolizado pela internet.

Enquanto tecemos estas considerações não temos dimensão de quanto essa doença ainda assolará as pessoas e nem sua morosidade, porém sabemos que mudou a perspectiva em relação ao sagrado em sua dimensão espacial. Acreditamos que o desdobramento de novas práticas sociais culturais e políticas a partir dessa pandemia possa tornar mais lúcida a nossa percepção de uma nova estruturação sócioespacial que se objetivarão nas configurações de paisagens, territórios associados à esfera do sagrado.

\section{REFERÊNCIAS}

BAUMAN, Zigmunt. 44 cartas ao mundo líquido. Rio de Janeiro: Editor Jorge Zahar, 2011, Edição Simplíssimo Livros ePub, 144 p.

BAUMAN, Zigmunt. Medo líquido. Rio de Janeiro: Editor Jorge Zahar, 2008, $181 \mathrm{p}$.

BAUMAN, Zigmunt. Modernidade líquida. Rio de Janeiro: Editor Jorge Zahar, 2001, $268 \mathrm{p}$.

BÍBLIA SAGRADA. Bíblia Sagrada: nova versão internacional. São Paulo: Sociedade Bíblica Internacional, 2002, 1002 p.

BRASIL tem 4.205 mortes e 61.888 casos confirmados de coronavírus, diz ministério. G1, Rio de Janeiro, 26 abr. 2020, Bem Estar, Coronavírus, s. n. Disponível em: https://g1.globo.com/bemestar/coronavirus/noticia/2020/04/ 26/brasil-tem-4205-mortes-e-61888-casos-de-coronavirus-dizministerio.ghtml. Acesso em: 26/04/2020.

CASSIRER, Ernst. Filosofia das formas simbólicas II: o pensamento mítico. São Paulo: Editora Martins Fontes, 2004, 412 p.

CHAGAS, Tiago. Após desafiar autoridades, Malafaia recua e orienta pastores a suspenderem cultos. Gospel Mais, São Paulo, 19 mar. 2020, Brasil, s.n. Disponível em: https://noticias.gospelmais.com.br/apos-desafiar-autoridadesmalafaia-recua-e-orienta-suspencao-cultos-131582.html. Acesso em: 20/03/2020. 
Corona virus e a igreja dos palcos. [S. l.: s. n.], 2020. 1 vídeo (5m26s). Publicado pelo canal Alessandro Vilas Boas. Disponível em: https://www.youtube.com/wa tch?v=pneiB7YZxH8. Acesso em: 20/03/2020.

CORRÊA, Roberto Lobato; ROSENDAHL, Zeny. A geografia cultural brasileira: uma avaliação preliminar. Revista da ANPEGE, [S.l.], v. 4, n. 04, p. 73-88, jul. 2017. ISSN 1679-768X. DOI: https://doi.org/10.5418/RA2008.0404.0005. Disponível em: http://ojs.ufgd.edu.br/index.php/anpege/article/view/66oo. Acesso em: 25 jun. 2020.

COSGROVE, Denis. A geografia está em toda a parte: cultura e simbolismo nas paisagens humanas. In: CORREA, Roberto Lobato; ROSENDAHL, Zeny (orgs.). Paisagem, tempo e cultura. Rio de Janeiro, EdUERJ, p. 92-124, 1998.

COUlangeS, Numa-Denys Fustel de. A cidade antiga. São Paulo: eLibris, 2006, $447 \mathrm{p}$.

DIP, Andreia et al. O lobby dos evangélicos contra o fechamento das igrejas. Pública, São Paulo, 07 abr. 2020, Especial coronavírus. Disponível em: https://apublica.org/2020/04/o-lobby-dos-evangelicos-contra-o-fechamentodas-igrejas/?mc_cid=4c2d481d3e\&mc_eid=f3b75a9d51. Acesso em: 08/04/2020.

DUQUE, João Manoel Correia Rodrigues. Devotio postmoderna: da cibergnose à compaixão. In: QUEIROZ, José; GUEDES, Maria Luiza; QUINTILIANO Angela Maria Lucas (orgs.). Religião, modernidade e pós-modernidade: interfaces, novos discursos e linguagens. Aparecida, SP: Ideias \& Letras, p. 7596, 2012.

ELIADE, Mircea. Tratado de história das religiões. 3. ed. São Paulo: Editora Martins Fontes, 2008, 479 p.

ELIADE, Mircea. O mito do eterno retorno: arquétipos e repetição. Lisboa: Edições 70, 1985, 174 p.

ELIADE, Mircea. O sagrado e o profano: a essência das religiões. Lisboa: Livros do Brasil, 1979. (Coleção vida e cultura), 235 p.

EUA têm dobro do número de casos por coronavírus que a China. R7.com. São Paulo, 26 mar. 2020, Coronavírus, s.n. Disponível em: https://noticias.r7.com/saude/eua-tem-dobro-do-numero-de-casos-porcoronavirus-que-a-china-31032020. Acesso em: 02/04/2020.

EVENTO fechado em igreja evangélica espalha coronavírus por toda a França. Época, Rio de Janeiro, 10 mar. 2020, Mundo, s. n. Disponível em: https://epoca.globo.com/mundo/evento-fechado-em-igreja-evangelicaespalha-coronavirus-por-toda-franca-24296728. Acesso em: 20/03/2020.

GIL FILHO, Sylvio Fausto. Espaço Sagrado: estudos em geografia da religião. Curitiba: Ibpex, 2008, 146 p. 
GREGÓRIO, Neto. Igreja na Coreia do Sul que não cancelou cultos está ligada à dezenas de casos de coronavírus. Gospel Prime, São Paulo, 19 mar. 2020, Mundo, s. n. Disponível em: https://www.gospelprime.com.br/igreja-na-coreiado-sul-que-nao-cancelou-cultos-esta-ligada-a-dezenas-de-casos-decoronavirus/. Acesso em: 20/03/2020.

GROSS, Eduardo. Contribuição das definições do sagrado de Rudolf Otto e Mircea Eliade para o estudo da literatura. Graphos, João Pessoa, v. 19, n. 1, p. 41-56, 2017.

GRYBOSK, Michael. Hundreds attend Ohio church's drive-in church worship service. The Christian Post, Washington, Estados Unidos, 22 mar. 2020, Coronovirus, s. n. Disponível em: https://www.christianpost.com/news/hundr eds-attend-ohio-churchs-drive-in-church-worship-service.html. Acesso em: 01/04/2020.

HAESBAERT, Rogério. O mito da desterritorialização: Do "fim dos territórios" à multiterritorialidade. 11. ed. Rio de Janeiro: Bertrand Brasil, 2019, 396 p.

HAESBAERT, Rogério. Viver no limite: território e multi/ transterritorialidade em tempos de in-segurança e contenção. Rio de Janeiro: Bertrand Brasil, 2014. 437 p.

HAYWARD, John. China Uses Coronavirus Crisis to Bulldoze Churches and Temples. Breitbart, Los Angeles, Estados Unidos, 25 mar 2020, World, s. n. Disponível em: https://www.breitbart.com/nationalsecurity/2020/03/25/china-uses-coronavirus-crisis-to-bulldoze-churches-andtemples/. Acesso em: 02/04/2020.

HEAD, Timothy. Home church: quarantine can be a time to draw closer to God. The Christian Post, Washington, Estados Unidos, 24 mar. 2020, Coronavirus, s. n. Disponível em: https://www.christianpost.com/voices/homechurch-quarantine-can-be-a-time-to-draw-closer-to-god.html. Acesso em: 02/04/2020.

HISSA, Cássio Eduardo Viana. A mobilidade das fronteiras: inserções da geografia na crise da modernidade. Belo Horizonte: Editora UFMG, 2002, 316p.

IGREJA sem nome, denominação, pastor ou dízimo faz sucesso em "território" de Padre Cícero. Gospel Mais, São Paulo, o4 jan. 2011, Brasil, s. n. Disponível em: https://noticias.gospelmais.com.br/igreja-sem-nome-denominacao-pastordizimo-sucesso.html. Acesso em: 20/03/2020.

KONG, Lily. In search of permanent homes: Singapore's house churches and the politics of space. Urban Studies, Singapore, v. 39, n. 9, p. 1573-1586, 2002. DOI: 10.1080 / 00420980220151664. Disponível em: https://ink.library.smu.edu.sg/soss_research/1730. Acesso em: 25/o6/20.

MACHADO, Leandro. De cultos online a 'não leia notícias sobre pandemia': como as religiões estão lidando com o coronavírus no Brasil. BBC Brasil, São 
Paulo, 17 mar. 2020, s. n. Disponível em https://www.bbc.com/portuguese/brasil-51920196. Acesso em 20/03/2020.

MAIA, Kléber. O ensino bíblico na igreja e na internet. Gospel Prime, São Paulo, 19 mar. 2020, Brasil, s. n. Disponível em:

https://www.gospelprime.com.br/o-ensino-biblico-na-igreja-e-na-internet/. Acesso em: 20/03/2020.

MARTINS, Dan. Cresce o número de evangélicos sem denominação e em igrejas pequenas. Gospel Mais, São Paulo, 02 jul. 2012, Brasil, s. n. Disponível em: https://noticias.gospelmais.com.br/cresce-numero-evangelicos-semdenominacao-igrejas-pequenas-38904.html. Acesso em: 20/03/2020.

MOTTA, Rodrigo. Coronavírus: uma oportunidade para a missão digital. Gospel Prime, São Paulo, 13 mar. 2020, Brasil, s. n. Disponível em: https://www.gospelprime.com.br/coronavirus-uma-oportunidade-para-amissao-digital/.

OLIVEIRA, Jefferson Rodrigues de. O on e o off da fé na hipermodernidade: a religião e novas interfaces do sagrado na era 2.o: o caso do Vale do Paraíba, São Paulo. Orientadora: Zeny Rosendahl, 2017, 261f. Tese (Doutorado em Geografia), Universidade Estadual do Rio de Janeiro, Rio de Janeiro, 2017.

OTTO, Rudolf. O sagrado: os aspectos irracionais na noção do divino e sua relação com o racional. 2. ed. São Leopoldo: Sinodal/EST; Petrópolis: Vozes, 2007, 224 p.

PASTOR decide batizar jovem em casa devido a restrições pelo coronavírus, na Itália. Guiame.com.br, [s. l.], 17 mar. 2020, Mundo, s. n. Disponível em: https://guiame.com.br/gospel/mundo-cristao/pastor-decide-batizar-jovemem-casa-devido-restricoes-pelo-coronavirus-na-italia.html. Acesso em: 20/03/2020.

RODRIGUES Maycson. Coronavírus e a igreja: é certo cancelar o culto? Gospel Prime, São Paulo, 16 mar. 2020, Opinião, s. n. Disponível em:

https://www.gospelprime.com.br/coronavirus-e-a-igreja-e-certo-cancelar-oculto/. Acesso em: 20/03/2020.

ROSENDAHL, Zeny. O sagrado e sua dimensão espacial. In: CASTRO, I. E.; GOMES, P. C. C.; CORRÊA, R. L. (orgs.) Olhares geográficos: modos de ver e viver o espaço. Rio de Janeiro: Bertrand Brasil, p. 73-100, 2012, 192 p.

ROSENDAHL, Zeny. O sagrado e o espaço. In: CASTRO, I. E.; GOMES, P. C. C.; CORRÊA, R. L. (orgs.) Explorações geográficas: percursos no fim do século. 3. ed. Rio de Janeiro: Bertrand Brasil, p. 119-154, 2006, 368 p.

SERNA, Ricardo. Igreja que promete 'imunização' contra coronavírus pode ser enquadrada por charlatanismo, diz MP. BBC Brasil, Londres, 02 mar. 2020, 
Notícias, s.n. Disponível em: https://www.bbc.com/portuguese/brasil51708763. Acesso em: 20/03/2020.

TUAN, Yi-Fu. Espaço e lugar: a perspectiva da experiência. Londrina: Eduel, 2013, 248 p.

Recebido em 2 de maio de 2020

Aceito em 9 de julho de 2020 